\title{
Future treatment strategies of aggressive pituitary tumors
}

\author{
Steven W. J. Lamberts • Leo J. Hofland
}

Published online: 12 November 2008

(C) The Author(s) 2008. This article is published with open access at Springerlink.com

\begin{abstract}
While surgery remains the first-line treatment of most aggressive pituitary adenomas, medical therapy is important as second-line or adjunctive therapy in a large proportion of patients. Dopamine agonists (DAs) are the best treatment for prolactinomas, but when DAs are not tolerated, new somatostatin receptor subtype $5\left(\mathrm{SSTR}_{5}\right)$ inhibitors may offer an alternative in the future. Unfortunately, these are unlikely to be effective in DA-resistant prolactinomas. In acromegaly, the existing somatostatin analogs, octreotide and lanreotide, will remain the medical treatment of choice for the foreseeable future. There is an urgent need for medical therapies in Cushing's disease, and the SSTR $_{5}$ analogs could offer an effective treatment in a proportion of patients within the next few years. Finally, the medical management options for non-functioning pituitary adenomas are also very limited, and a new chimeric agent with activity towards dopamine receptors, $\mathrm{SSTR}_{5}$ and $\mathrm{SSTR}_{2}$ may help reduce adenoma recurrence in the future.
\end{abstract}

Keywords Pituitary adenoma - Surgery ·

Pharmacotherapy $\cdot$ Radiotherapy $\cdot$ Chemotherapy

\section{Introduction}

Aggressive pituitary tumors are difficult to manage. A wide range of treatments are used including transsphenoidal surgery (and transcranial surgery when the lesions occur

S. W. J. Lamberts $(\varangle) \cdot$ L. J. Hofland

Department of Internal Medicine, Division of Endocrinology,

Erasmus Medical Center, 230's Gravendijkwal, 3015 CE

Rotterdam, The Netherlands

e-mail: s.w.j.lamberts@erasmusmc.nl mainly outside the sella), dopamine agonists (DAs) for prolactinomas and somatostatin analogs (SSAs) for other types of adenomas, radiotherapy as third-line treatment, and chemotherapy in some rare aggressive tumors, and sometimes a combination of these treatment modalities is required to control the tumor growth and recurrence. However, improvements in the management of these tumors are needed, and in particular for the treatment of aggressive tumors. In this short paper we review some promising medical therapies for the different types of pituitary tumors.

\section{Prolactinomas}

The vast majority of prolactinomas, including invasive macro-adenomas, are adequately controlled with dopamine agonists (DAs). There are three potential receptor targets for drug therapy of prolactinomas- $-\mathrm{DA}_{2}$ receptors, somatostatin receptors subtypes 2 and $5\left(\mathrm{SSTR}_{2}\right.$ and $\left.\mathrm{SSTR}_{5}\right)$, and estrogen receptors $\left(\mathrm{E}_{2}-\mathrm{R}\right)$. The $\mathrm{DA}_{2}$ receptors are expressed in almost all prolactinomas and are the target for much current therapy, but some patients are resistant to DA and many do not tolerate DA therapy.

SSTR are expressed in prolactinomas, but the majority express $\mathrm{SSTR}_{5}$ and not $\mathrm{SSTR}_{2}$ [1]. When quantified, $\mathrm{SSTR}_{5}$ mRNA was detected at 40-fold higher concentrations than $\mathrm{SSTR}_{2}$ mRNA ( $\mathrm{SSTR}_{1}$ was also expressed in prolactinomas but the significance of this is not known) [1]. This expression pattern means that established somatostatin analogs (SSAs) such as octreotide and lanreotide that bind primarily to $\mathrm{SSTR}_{2}$ are ineffective in suppressing prolactin secretion from these adenomas [2]. This has been demonstrated by comparing the inhibition of prolactinomas by octreotide and the experimental compound pasireotide 
(SOM-230), which has 40-fold greater binding affinity to $\mathrm{SSTR}_{5}$ than octreotide. This study showed slight inhibition of prolactin secretion in one out of three adenomas by octreotide, while pasireotide significantly inhibited prolactin secretion in all three adenomas [2]. Unfortunately, potent $\mathrm{SSTR}_{5}$ inhibitors may not be of value in treating prolactinomas, because their potential efficacy is most needed for treating DA-resistant prolactinomas, and most of these prolactinomas appear to express no (or low levels) of $\mathrm{SSTR}_{5}$ and are also resistant to SSAs that bind to this receptor (Fig. 1) [1]. Furthermore, there was no additive effect on prolactin secretion when a $\mathrm{SSTR}_{5}$ inhibitor was added to a DA [1].

Prolactinomas also express estrogen receptors $\left(\mathrm{E}_{2}-\mathrm{R}\right)$ [3], and the frequency of this observation is similar in men and women (in a small-scale analysis, $60 \%$ of tumors from men were $E_{2}$-R-positive and $67-90 \%$ from women were $\mathrm{E}_{2}$-R-positive) [4]. In vitro studies have been inconclusive on the effects of selective $\mathrm{E}_{2}-\mathrm{R}$ modulators on prolactinomas [5]. Furthermore, the incidence of $\mathrm{E}_{2}-\mathrm{R}$ on recurrent prolactinoma tumors was significantly reduced $(P=0.03)$ [4], and this suggests that DA-resistant adenomas would be resistant to anti-estrogens.

Other potential therapies for prolactinomas (such as gene therapy, molecular therapeutics or the use of nerve growth factor) are in the very early stages of discovery [5].

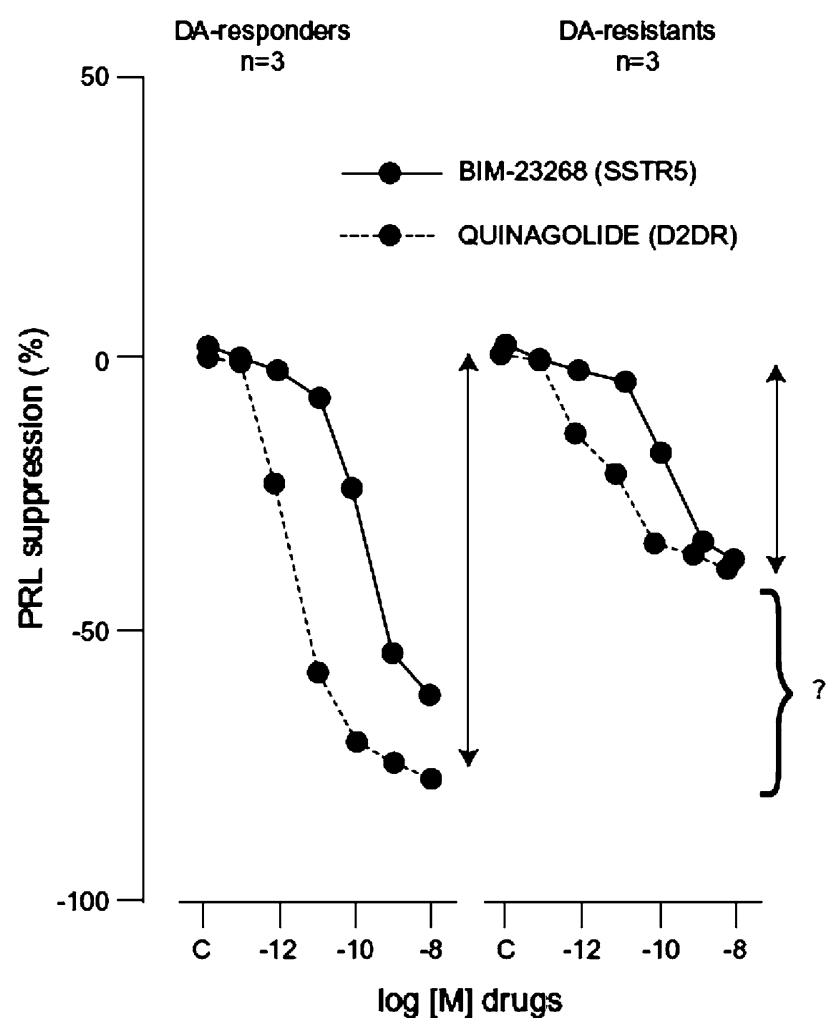

Fig. 1 Effect of $\mathrm{SSTR}_{5}$-specific analog on prolactin secretion from DA-susceptible and DA-resistant human prolactinomas. From Jaquet et al. [1]

\section{Acromegaly}

Although pegvisomant treatment normalises insulin-like growth factor (IGF)-1 in a high proportion of patients with acromegaly [6], it has no effect on tumor size, and SSAs remain the first-choice medical therapy for acromegaly, especially in large and/or aggressive tumors.

Virtually all acromegaly tumors express both $\mathrm{SSTR}_{5}$ and $\operatorname{SSTR}_{2}$ (and a smaller proportion express $\mathrm{SSTR}_{1}$ or $\mathrm{SSTR}_{3}$ ) [2]. In theory, molecules that bind to both $\mathrm{SSTR}_{5}$ and $\mathrm{SSTR}_{2}$ may provide improved efficacy in acromegaly (existing SSAs bind most potently to $\mathrm{SSTR}_{2}$ ). However, measurements of apoptosis in somatotroph tumor cells have shown that octreotide and a super-selective SSTR $_{2}$ analog promote apoptosis to a similar degree, while a super-selective SSTR $_{5}$ analog is ineffective (Fig. 2) [7]. Both analogs did arrest growth, measured by an increase in p27 and decrease in cyclin D1 expression, and so both receptors appear to be involved in the cytostatic action of SSAs [7]. The most important tumor shrinking effects of SSAs appear, therefore, to be caused by binding to the $\mathrm{SSTR}_{2}$, and agents with combined $\mathrm{SSTR}_{5}$ and $\mathrm{SSTR}_{2}$ binding are unlikely to be more effective. In tumors that are resistant to octreotide or lanreotide, $\mathrm{SSTR}_{5}$ activation by pasireotide may, in a minority of patients, further lower $\mathrm{GH}$ and IGF-1 levels. With the expression of other SSTR subtypes in a proportion of acromegaly tumors, and with suggestions that apoptosis may also be mediated through these other receptor subtypes [8], future $\mathrm{SSTR}_{3}$ analogs may be useful in a small proportion of unresponsive cases.

\section{Cushing's disease}

Surgery is the treatment of choice for most patients with Cushing's disease, but when surgery fails to control the disease, there are no proven effective medical treatments [9].

Corticotropinomas often express dopamine receptors and/or SSTR 5 . In Nelson's syndrome (Cushing's disease treated with total adrenalectomy, in which pituitary expansion occurs and ACTH levels increase), treatment with the DA cabergoline has been shown to normalize plasma adrenocorticotrophin (ACTH) levels and eliminate the tumor within 1 year, but only when the dose of cabergoline was increased to $2 \mathrm{mg} /$ week [10]. When cabergoline was withdrawn, ACTH levels increased [10]. In addition, many years ago, infusion of somatostatin was also shown to reduce plasma ACTH in five patients with Nelson's syndrome by approximately $50 \%$ [11], and SSAs may also reduce ACTH level and improve symptoms in these patients [12].

However, in the majority of patients with Cushing's disease who do not have Nelson's syndrome, the 


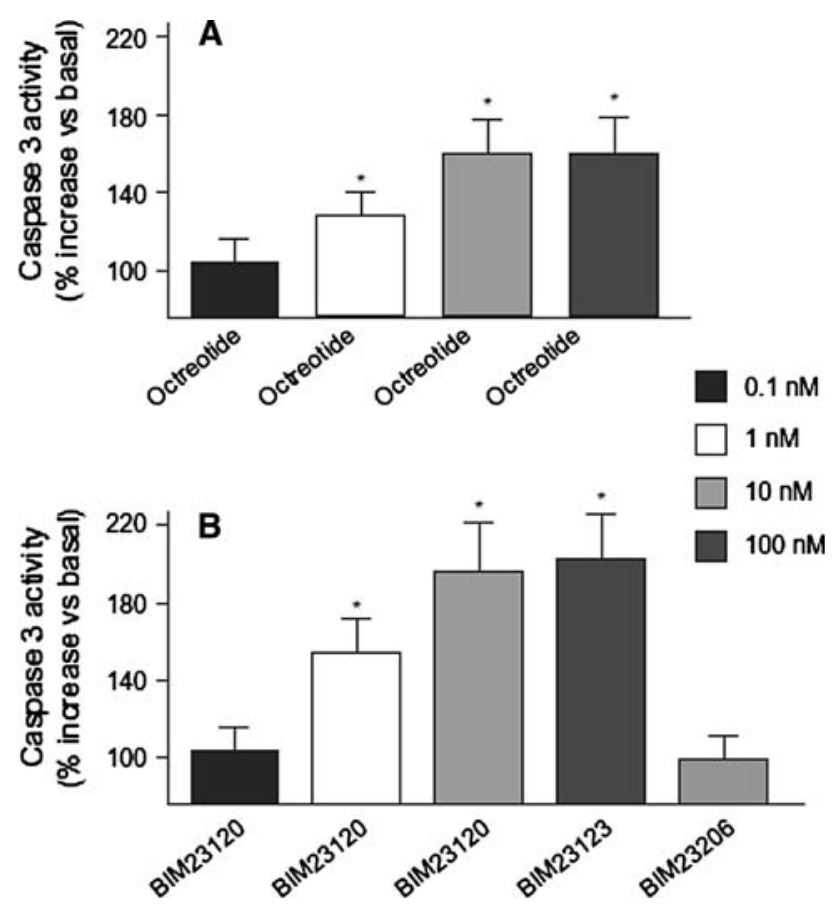

Fig. 2 Pro-apoptotic effects of different somatostatin analogs in human somatotroph tumors. From Ferrante et al. [7]

administration of octreotide had no beneficial effect on ACTH levels, tumor volume or symptoms $[12,13]$. This is because most tumors express mainly $\mathrm{SSTR}_{5}$ and not $\mathrm{SSTR}_{2}$ - demonstrated by the in vitro minor inhibition of ACTH release (decrease of $28 \%$ ) by octreotide in one out of five tumors, and the greater reduction of ACTH release (by 30-40\%) by pasireotide in three out of five tumors [14]. A second study confirmed the ACTH suppressing effects of pasireotide (suppressed ACTH release by $23-56 \%$ in five out of six tumor cell cultures) and showed suppression of cell proliferation of $10-70 \%$ [15]. These preclinical results suggest a possible role for $\mathrm{SSTR}_{5}$ analogs in the treatment of some patients with Cushing's disease, but clearly, clinical studies are needed. Preliminary clinical data have reported decreases in free urinary cortisol in patients with de novo or persistent/recurrent Cushing's disease after pasireotide administration [9].

Expression of $\mathrm{DA}_{2}$ receptors and $\mathrm{SSTR}_{5}$ are expressed similarly in micro- and macro-adenomas. However, recent work shows that the subgroup of largest corticotroph adenomas (Wilson and Hardy classification Stage III-IV) showed a near-complete loss of somatostatin and dopamine receptor expression [16], so other treatment options are still needed for these aggressive adenomas.

Retinoic acid has been shown to inhibit corticotroph tumor growth and ACTH release in experimental Cushing's disease (probably via inhibition of the transcription factors Ap-1 and Nur7 [7, 17] but the potential clinical value of this agent has not been determined.
To date, surgery and radiotherapy remain the treatments of choice for Cushing's disease, and while agents with combined $\mathrm{SSTR}_{5}$ and $\mathrm{SSTR}_{2}$ binding activity could provide a useful medical therapy for non-responsive or recurring adenomas, their efficacy is not yet proven.

\section{Non-functioning pituitary adenomas}

Non-functioning pituitary adenomas (NFPA) represent approximately one-third of pituitary tumors. Transsphenoidal surgery is the first-line treatment, but removal of the tumor is incomplete in approximately $50 \%$ of these adenomas-many NFPA progress to macroadenomas before they are detected, as the first symptoms are often compressive symptoms. Treatment with bromocriptine or octreotide has been relatively unsuccessful in producing tumor shrinkage $[18,19]$, and so medical therapies are still sought to prevent regrowth of the tumor after partial removal by surgery.

As with many other adenomas described here, NFPA express dopamine receptors and somatostatin receptors-in the case of NFPA, $\mathrm{SSTR}_{2}$ and $\mathrm{SSTR}_{3}$ are frequently expressed. Therefore, a new chimeric agent (BIM-23A760; dopastatin) has been developed with activity towards dopamine receptors and somatostatin receptors (specifically, $\operatorname{SSTR}_{2}$ and $\mathrm{SSTR}_{5}$ ). This agent inhibited $\left[{ }^{3} \mathrm{H}\right]-$ thymidine uptake (a measure of cell growth) in $60 \%$ of NFPA cell cultures (mean decrease of 33.6\%) tested [20]. Inhibition with dopastatin was of a similar magnitude to inhibition with a combination of cabergoline and octreotide (Fig. 3). Furthermore, when an inhibitor of dopamine activity was added in these experiments, dopastatin still had an inhibitory effect on NFPA cells (but this was partially inhibited to about $50 \%$ of the effect). This shows that the effects of dopastatin on NFPA are mediated by binding to both the dopamine and the somatostatin receptors [20]. No markers for response to dopastatin were identified in this study [20].

The development of such chimeric molecules is an exciting development in the treatment of NFPA, and the results of future clinical trials are awaited with interest.

\section{Conclusions}

In prolactinomas, SSAs do not appear to offer any additional benefit to treatment with DAs and are likely to be ineffective in DA-resistant tumors. Selective agents for $\mathrm{SSTR}_{5}$ may be useful in the future for patients that do not tolerate DA therapy, but other medical therapies that could replace or enhance treatment with DAs are many years away. In acromegaly, medical therapy with the existing SSAs and pegvisomant is excellent. Future studies may tell 


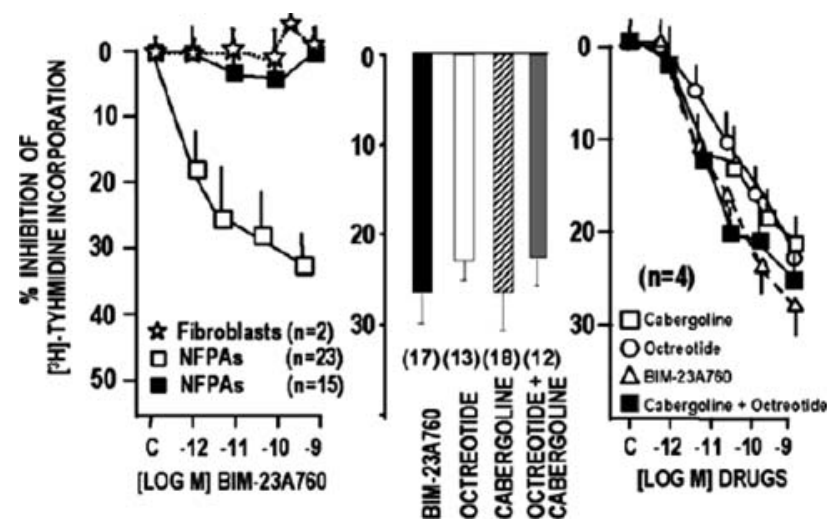

Fig. $3\left[{ }^{3} \mathrm{H}\right]$-thymidine uptake inhibition from cell culture of 38 nonfunctioning pituitary adenomas by cabergoline, octreotide and dopastatin. From Florio et al. [20]

us if SSTR $_{5}$ analogs will improve on the efficacy of currently available agents. SSTR $_{5}$ analogs, alone or in combination with DAs, may play a role in the future medical management of Cushing's disease, but not in the most aggressive tumors, and ongoing trials may elucidate the future role of such agents. Until then, surgery and radiotherapy will remain the mainstay of treatment for these tumors. In NFPA, there is a real need for effective medical therapies, and the new chimeric DA-SSA dopastatin is an exciting development that, if proven in the clinic, could become a very important tool in the management of NFPA. The precise place of such chimeric agents in the future treatment of NFPA is not known but initially they may be most useful as a post-operative adjunct, especially when there are suspected tumor remnants.

Acknowledgments The authors take full responsibility for the content of the paper but thank Martin Gilmour, PhD (supported by Ipsen) for editorial assistance in the preparation of the initial draft of the manuscript and its subsequent revision.

Open Access This article is distributed under the terms of the Creative Commons Attribution Noncommercial License which permits any noncommercial use, distribution, and reproduction in any medium, provided the original author(s) and source are credited.

\section{References}

1. Jaquet P, Ouafik L, Saveanu A et al (1999) Quantitative and functional expression of somatostatin receptor subtypes in human prolactinomas. J Clin Endocrinol Metab 84(9):3268-3276. doi: 10.1210/jc.84.9.3268

2. Hofland LJ, van der Hoek J, van Koetsveld PM et al (2004) The novel somatostatin analog SOM230 is a potent inhibitor of hormone release by growth hormone- and prolactin-secreting pituitary adenomas in vitro. J Clin Endocrinol Metab 89(4):1577-1585. doi: 10.1210/jc.2003-031344

3. Chaidarun SS, Swearingen B, Alexander JM (1998) Differential expression of estrogen receptor-beta (ER beta) in human pituitary tumors: functional interactions with ER alpha and a tumor- specific splice variant. J Clin Endocrinol Metab 83(9):33083315. doi: $10.1210 /$ jc.83.9.3308

4. Kaptain GJ, Simmons NE, Alden TD, Lopes MB, Vance ML, Laws ER (1999) Estrogen receptors in prolactinomas: a clinicopathological study. Pituitary 1(2):91-98. doi:10.1023/A:1009903 603495

5. Gillam MP, Molitch ME, Lombardi G, Colao A (2006) Advances in the treatment of prolactinomas. Endocr Rev 27(5):485-534. doi:10.1210/er.2005-9998

6. van der Lely AJ, Hutson RK, Trainer PJ et al (2001) Long-term treatment of acromegaly with pegvisomant, a growth hormone receptor antagonist. Lancet 358(9295):1754-1759. doi:10.1016/ S0140-6736(01)06844-1

7. Ferrante E, Pellegrini C, Bondioni S et al (2006) Octreotide promotes apoptosis in human somatotroph tumor cells by activating somatostatin receptor type 2. Endocr Relat Cancer 13(3): 955-962. doi:10.1677/erc.1.01191

8. Sharma K, Patel YC, Srikant CB (1996) Subtype-selective induction of wild-type p53 and apoptosis, but not cell cycle arrest, by human somatostatin receptor 3. Mol Endocrinol 10(12): 1688-1696. doi:10.1210/me.10.12.1688

9. Hofland LJ (2008) Somatostatin and somatostatin receptors in Cushing's disease. Mol Cell Endocrinol 286(1-2):199-205. doi: 10.1016/j.mce.2007.10.015

10. Pivonello R, Faggiano A, Di Salle F, Filippella M, Lombardi G, Colao A (1999) Complete remission of Nelson's syndrome after 1-year treatment with cabergoline. J Endocrinol Invest 22(11): 860-865

11. Tyrrell JB, Lorenzi M, Gerich JE, Forsham PH (1975) Inhibition by somatostatin of ACTH secretion in Nelson's syndrome. J Clin Endocrinol Metab 40(6):1125-1127

12. Lamberts SW, Uitterlinden P, Klijn JM (1989) The effect of the long-acting somatostatin analogue SMS 201-995 on ACTH secretion in Nelson's syndrome and Cushing's disease. Acta Endocrinol (Copenh) 120(6):760-766

13. Ambrosi B, Bochicchio D, Fadin C, Colombo P, Faglia G (1990) Failure of somatostatin and octreotide to acutely affect the hypothalamic-pituitary-adrenal function in patients with corticotropin hypersecretion. J Endocrinol Invest 13(3):257-261

14. Hofland LJ, van der Hoek J, Feelders R et al (2005) The multiligand somatostatin analogue SOM230 inhibits ACTH secretion by cultured human corticotroph adenomas via somatostatin receptor type 5. Eur J Endocrinol 152(4):645-654. doi:10.1530/eje.1.01876

15. Batista DL, Zhang X, Gejman R et al (2006) The effects of SOM230 on cell proliferation and adrenocorticotropin secretion in human corticotroph pituitary adenomas. J Clin Endocrinol Metab 91(11):4482-4488. doi:10.1210/jc.2006-1245

16. de Bruin C, Pereira AM, Feelders R et al (2008) Co-expression of dopamine and somatostatin receptor subtypes in human corticotroph adenomas in ENDO. San Francisco, USA

17. Paez-Pereda M, Kovalovsky D, Hopfner U et al (2001) Retinoic acid prevents experimental Cushing syndrome. J Clin Invest 108(8):1123-1131

18. Bevan JS, Webster J, Burke CW, Scanlon MF (1992) Dopamine agonists and pituitary tumor shrinkage. Endocr Rev 13(2):220 240. doi:10.1210/er.13.2.220

19. de Bruin TW, Kwekkeboom DJ, Van't Verlaat JW et al (1992) Clinically nonfunctioning pituitary adenoma and octreotide response to long term high dose treatment, and studies in vitro. J Clin Endocrinol Metab 75(5):1310-1317. doi:10.1210/jc.75.5.1310

20. Florio T, Barbieri F, Spaziante R et al (2008) Efficacy of a dopamine-somatostatin chimeric molecule, BIM-23A760, in the control of cell growth from primary cultures of human nonfunctioning pituitary adenomas: a multi-center study. Endocr Relat Cancer 15(2):583-596. doi:10.1677/ERC-07-0271 